\title{
Dubbelbespreking: Gezelschapsspel of monsterverbond?
}

\author{
HERKOMST EN ROL VAN HET \\ ROMANTISCH-MODERNE KUNSTBEGRIP
}

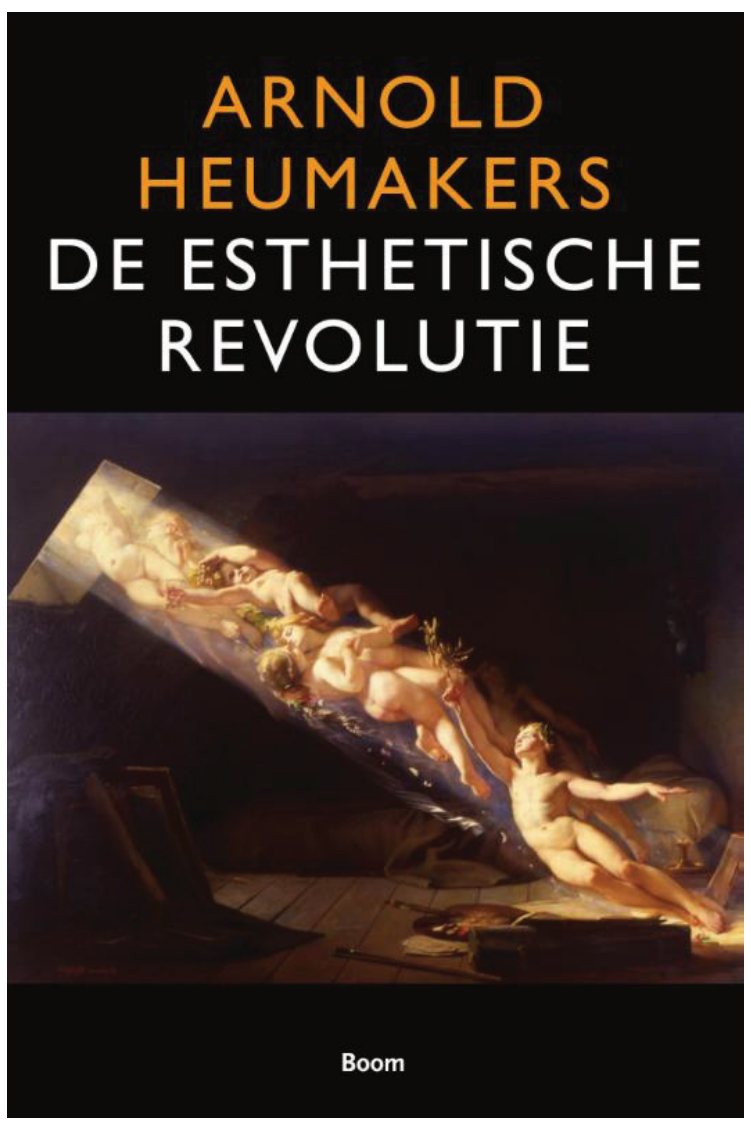

Arnold Heumakers

De esthetische revolutie. Hoe Verlichting

en Romantiek Kunst uitvonden

Boom, 2015, 502 pp., € 39,90

ISBN 9789089534507

\section{Peter Henk René} Steenhuis Gude

door het beeld door het woord

Peter Henk Steenhuis en René Gude

Door het beeld. Door het woord

ISVW, 20I5, 4I6 pp., € 39,50

ISBN 9789491693502

Bij Moritz, Goethe en Schiller wordt autonomie het kenmerkende verschil tussen ware kunst en producten van de nieuwe massacultuur, tussen echte kunstenaars en hun commerciële collega's, bij wie het niet om zuivere kunst gaat, maar om amusement en financieel gewin. Met de autonomie van de kunst ontstaat dus ook de dichotomie tussen hoge en lage cultuur, waarmee we nog altijd niet goed raad weten. ${ }^{\mathrm{I}}$ 
De dubbelzinnige waardering die we vandaag voor de 'nieuwe media' hebben, geldt evengoed voor het Westers kunstbegrip. Niettemin verleent dit uit de achttiende eeuw daterende kunstbegrip door Heumakers aangeduid als 'romantisch' - de hedendaagse kunst nog immer een vanzelfsprekend aura. ${ }^{2}$ Dit zijn stellingen die Heumakers in zijn omvangrijke proefschrift op erudiete wijze onderbouwt. De bij het ISVW in hetzelfde jaar verschenen bundel Door het beeld, dringt zich op als testcase om de aard van dit kunstbegrip nader te bezien. In deel I doet Trouwjournalist Peter Henk Steenhuis verslag van zijn gesprekken met eenentwintig kunstenaars. In deel 2 reflecteert filosoof René Gude daar uitvoerig op.

Met die vanzelfsprekende combinatie filosofie-en-kunst stuiten we direct op de crux van Heumakers' 'ideeënhistorische reconstructie': de esthetische revolutie die dit moderne kunstbegrip voortbracht, vooral bekend uit de Kritiek van het oordeelsvermogen (I790) van Immanuel Kant, blijkt het bijproduct van een langdurig Verlichtingsdebat dat zich in het achttiende-eeuwse Noord-Europa voltrok en waarin de filosofie op zoek was naar een nieuwe legitimatie. ${ }^{3}$ In zijn inleiding op de twaalf kernhoofdstukken over het wispelturige debat tussen filosofen en dichters, stelt Heumakers dat het feitelijk om twee esthetische revoluties gaat. ${ }^{4}$ De eerste betrof het autonoom worden van het Schone of de Kunst, als een apart domein, 'waar eigen regels en wetten van kracht zijn die niet automatisch dezelfde zijn als de regels en wetten die in de rest van de samenleving gelden. Wie deze autonomie aanvaardt, gaat ervan uit dat kunst en literatuur moeten worden gezien als in principe onafhankelijk van moraal, religie, politiek en wetenschap'. ${ }^{5}$ Daarbij werd de poëzie beschouwd 'als de "geest" of kern van alle kunsten'. ${ }^{6}$ De tweede 'esthetische' revolutie die Heumakers onderscheidt trachtte deze verbroken band met de wereld te herstellen, door Kunst het vermogen toe te delen om de beschaving opnieuw uit te vinden en te verbeteren. Het is deze pretentie die vanaf dan voor een permanente crisis in de Kunst zorgt. Tegelijk creëert dit nieuwe kunstbegrip extreem hoge verwachtingen ten aanzien van kunst en kunstenaar. ${ }^{7}$

In het hierna volgende zal ik twee dingen doen. Ten eerste de hedendaagse opvattingen over Kunst, zoals neergelegd in de bundel van Steenhuis en Gude, beschouwen in het licht van Heumakers naspeuringen over het moderne kunstbegrip. Vervolgens ga ik in op Heumakers' publicatie, waarbij zowel de breuk met het klassieke kunstbegrip die zich begin achttiende eeuw voltrok aan bod komt, als ook de relevantie van dit achttiende-eeuwse filosofische debat voor de visuele kunsten en nieuwe media. Tot slot zal ik beweren dat we dit romantische kunstbegrip bij de wetenschappelijke bestudering van mediageschiedenis en huidige populaire cultuur het beste links kunnen laten liggen.

\section{De ISVW-bundel vanuit Heumakers}

Het romantische kunstbegrip is een merkwaardig samengesteld geheel, een historisch gedateerd begrip dat niet opgaat voor de kunstwerken van vóór die tijd. ${ }^{8}$ Het begrip is, Heumakers parafraserend, ingebed in een semantische horizon gevormd door termen als originaliteit, expressiviteit, inspiratie, genialiteit, creativiteit, spontaniteit, scheppingskracht, spiritualiteit, individuele smaak, grensverleggend en kritisch vermogen, dat allemaal samen gaat met een vrijer gebruik van vormen en een verheven aandacht voor natuur, liefde en gemoedsuitstortingen. ${ }^{9}$ Kunst wordt gedreven door een heilig geloof in zowel haar onaanraakbaarheid als haar morele engagement, met de kunstenaar als haar eenzame profeet. In dat licht bezien vormen 
onderstaande opvattingen (ontleend aan de ISVW-publicatie met enkele paginanummers die daarop betrekking hebben) een perfecte illustratie van Heumakers stelling dat het romantischmoderne kunstbegrip nog steeds de eigentijdse kunstopvatting bepaalt:

Kunst heeft een ethische taak zoals de natuur redden (I8), patiënten troosten (23, 209), rust (208) en oorspronkelijkheid bieden (89), ontsnappen uit de dagelijkse sleur (94), ons terug voeren naar oorsprong en oermateriaal (89). Kunst vertelt je hoe je je voelt (90), werpt je terug op jezelf (I46), is de beste vertaling van een idee (20I), moet dubbele bodems hebben, vrolijk en agressief maken (227), is diepzinnig, meditatief, spiritueel, subliem, vergeestelijkt $(37,73,75,94,146,208,2 \mathrm{II}, \mathrm{I7I})$, neemt de functie van religie over (I47), of moet die juist vermijden (I99), heeft geen woorden nodig, is zichzelf $(287,272)$. De kunstenaar moet een verhaal toevoegen (I33), onze maatschappij interpreteren (I59, 20I), de kunstwereld tot onderwerp nemen (I68), het onzichtbare tonen (22I), bezigzijn met de ander (229), een ervaring teweeg brengen (268), het menselijk vermogen afbeelden (257). De kunstenaar moet zijn ego loslaten (76), of juist zijn innerlijke kunstenaarswereld uitdrukken $(25,67)$, voelt verdriet en woede over zijn tijd (I60), is een grote associatiemachine (I83), is zich bewust van zichzelf (I86), verdwijnt achter zijn werk (249), is een priester van de kunst (249), doorziet hoe de wereld in elkaar steekt (20I), wil niet tussen werk en kijker staan (32), wil de kijker uit zijn comfortzone trekken (67), woont in zijn werk (9I). Het maakproces moet onzichtbaar zijn, zo min mogelijk inmenging (32, 90, I43, 20I) onopgesmukte eerlijkheid tonen $(23,26)$, of juist een persoonlijke penseelstreek vormen (257), manipulatief zijn $(28,35)$, zich toeleggen op virtuoos schilderen (89), gruwelijke beelden juist mooi maken (159). Sinds de Verlichting is het bergafwaarts gegaan met de westerse cultuur (I55), hebben musea zich tussen kunstenaar en maatschappij gedrongen (9I), is kunst buiten de maatschappij komen te staan (85). ${ }^{\text {IO }}$

De rommelige verzameling van opinies die veel kunstenaars erop na houden is het resultaat van amateuristisch gefilosofeer door professionals die veelal op kunstacademies zijn opgeleid en die op een nogal religieuze manier in 'de Kunst' geloven. Nogal wat kunstenaars strooien diepzinnige oneliners van bekende filosofen, theologen, dichters of allerhande wetenschappers in het rond, terwijl ze de kunstgeschiedenis losjes gebruiken om hun eigen vernieuwende idee te profileren. ${ }^{\text {II }}$ Tegelijk zijn kunstenaars zelf zeer argwanend, zo merkt Gude op, gegeven het 'gezwatel', van 'internationaal vermaarde estheticaprofessors' en 'de ondoorgrondelijke taal waarin kunst wordt aangeprezen' in musea. ${ }^{\mathrm{I} 2}$

Zo'n heterogene verzameling van uitspraken vraagt dus om een scherpe geest die orde aanbrengt. 'Filosofie moet ervoor zorgen dat je met je verstand de goede dingen doet (...). Het verstand moet leren om zichzelf in bedwang te houden. ${ }^{\mathrm{I} 3}$ René Gude pleitte met deze uitspraak voor een geestelijke disciplinering in de omgang met Dood en Sterven - zijns inziens een levensnoodzaak om het overmatig denken, eindeloos praten, excessief interpreteren en grenzeloos speculeren krachtig in het gareel te houden. Opmerkelijk genoeg acht hij deze zelfdisciplinering niet van toepassing op de Kunst. Integendeel. 'Kunst', zegt hij 'daar moeten Woorden tegen aan'. ${ }^{\text {I4 }}$ Gude doet op dit punt weinig anders dan zijn Nederlandse collega-filosofen, die zichzelf beschouwen als de rechtmatige bemiddelaars en woordvoeders bij uitstek in het Kunstveld. 
Gude's inbreng in deel 2 van de bundel bestaat enerzijds uit het imponerend bespreken van grote filosofische kwesties (Kosmos, Wereld, Geest, Materie, Woord, Beeld) aan de hand van wat hij weet over de Mens, Geschiedenis, Religie, Biologie enzovoorts. Anderzijds is zijn stijl er voortdurend op gericht om datgene wat hij beweert te ondermijnen met uitspraken als 'ome Immanuel Kant, ook geen kleine jongen. ${ }^{\text {I5 }}$ Ergerniswekkend is ook het veelvuldig gebruik van verkleinwoorden en zijn soms bewust populaire taalgebruik ('wij burgo's', 'paplepelimpressies', 'hele blub ervaring'), of zijn duistere ('de druzigheid van ons gedoetje') en bovendien vaak weinig elegante ('volkomen kut', 'lekker smoezelig', 'klinkt geil en dat is het ook') uitspraken. Samen met zijn stokpaardjes over 'nomadisch en sedentair leven' vormt het geheel een illustratie van wat hij omschrijft als het effect van het 'onvolprezen kletsvermogen' en 'woordpoeperij', waarbij hij zich overigens wil onderscheiden van andere denkers die alles 'vrolijk door elkaar piemelen'. ${ }^{16}$

Over de vraag wat dat betekent voor Gude's bespiegelingen over Kunst kan ik kort zijn - hij ziet kunstenaar en filosoof als een logische tandem, twee figuren die elkaar in morele zin kunnen bijstaan. ${ }^{\text {I7 }}$ Gude sluit probleemloos aan bij allerlei gezond-verstand-items die de kunstenaars inbrengen. Dat gebeurt in hoofdstukken over 'Aandacht', 'Empathie', 'Heimwee', 'Inspiratie', 'Lust' en 'Mediatie', maar zonder daarin enige orde te scheppen. Dat loopt uit op zinnen als de volgende:

Ja, de vrije kunst die niet tot doel heeft om producten voor de kantoorbenodigdhedenwinkel voort te brengen waar mensen d'r lui liefdesbrieven mee kunnen schrijven, maar speciale artefacten - letterlijk 'kunstwerken' - waarmee kunstenaars, door te exposeren in openbare ruimten en privésfeer, andere wereldburgers een gelegenheid bieden tot een intervisie van twee wereldbeelden. ${ }^{\text {I8 }}$

Een andere kenmerkende zin is deze:

Ik neem aan dat kunstenaars ook beginnen met in het wilde weg of juist heel doelbewust indrukken op te doen die ze vervolgens tot uitdrukking brengen in het kunstwerk. Wetenschappers in ieder geval wel. Veel waarnemingen, al dan niet met gespecialiseerde apparaten, die in theorieën uitgedrukt worden. Olieverf en canvas zijn niet het materiaal waarmee de kunstenaar aan het werk gaat. Het eigenlijke materiaal van de kunst zijn de impressies (...). De artistieke expressie, het artefact, wordt op een tentoonstelling dan overigens weer een impressie voor de toeschouwers. ${ }^{\text {I9 }}$

En dan zwijg ik nog over tal van opmerkingen à la Loesje, zoals: '[e]en nomade met heimwee is echt de Sjors', of '[a]ls de Verlichting schaduwzijden heeft, is dimmen de beste strategie'. ${ }^{20}$

Wat uit Gudes volgzame woorden wel naar voren komt is dat kunstenaars inderdaad denken dat juist zij de wereld iets te bieden hebben. Dit ondanks het feit dat ze vaak niet méér weten dan gewone burgers en ook geen enkel specialisme hebben geleerd waaruit hun toegevoegde waarde blijkt. Dat berust inderdaad op een romantisch zelfbeeld en het wordt door filosofen in samenspraak met de moderne kunstwereld op een kritiekloze manier gesanctioneerd. Dat wordt nog eens bevestigd door Gude als hij schrijft: 'de kunstenaar probeert niet met taal of concepten 
houvast te vinden, maar met beelden routes uit te stippelen, handvatten te bieden, leuningen te maken die ons helpen grip te krijgen op de chaos' ${ }^{21}$ In een dergelijke visie fungeren kunstenaars nog immer als hogepriesters die vanuit hun superieure domein aan de wereld en haar burgers een bepaalde waarheid voorhouden. Slecht sporadisch schrijft Gude iets waarbij hij verder kijkt dan deze al vele malen gerecyclede opinies over Kunst en houdt hij de lezer voor dat het modernromantische kunstbegrip geen eeuwigheidswaarde heeft. Onder verwijzing naar 'de trainingsethiek van Aristoteles', schrijft Gude dat hij vermoedt dat de Romantiek ten einde loopt:

Als Ambachtelijkheid inderdaad aan een opmars bezig is, zowel in de samenleving als in de kunst, betekent dat dat we langzaam maar zeker loskomen van de romantische overwaardering van het individu, van de 'shortcut to romanticism'. (...) De gedachte dat talent, genialiteit, vanzelf komt bovendrijven, staat lijnrecht tegenover de opvatting dat alles wat boven het menselijke uitsteekt door mensen gemakkt moet worden. ${ }^{22}$

Dat lijkt me een mooi moment om terug te keren naar Heumakers.

\section{Heumakers en de geschiedenis der kunsten}

Het modern-romantische kunstbegrip is op tal van tegenstellingen gebouwd. Vanaf de achttiende eeuw start een slingerbeweging waarbij filosofen zich alternerend afzetten tegen wat ze als hun tegendeel opvatten. Die beweging kunnen we in Heumakers publicatie op de voet volgen. ${ }^{23}$ Zo bezien is de geschiedenis van het modern-romantische kunstbegrip een vat vol tegenstrijdigheden, dat haar bestaansrecht aan een antagonistisch fundament ontleent. Heumakers is overigens niet de enige die dat betoogt. ${ }^{24} \mathrm{Hij}$ gaat er net als veel anderen vanuit dat deze beweging door een harde breuk in de Europese geschiedenis veroorzaakt wordt. Hij doet een aantal aannames, waarvan ik er drie noem: I) dat met Descartes een Wetenschappelijke Revolutie start die het wereldbeeld mechaniseert, 2) dat er vanaf de achttiende eeuw geen geschriften meer zijn die op de klassieke of vroegmoderne kunst van schilderen, tekenen en bouwen voort denken; 3) dat Plato leidend is in het nadenken over schoonheid en kunst. Een korte toelichting hierop moet volstaan.

Vanwege zijn 'cogito ergo sum' wordt Descartes vaak gezien als personificatie van de epistemologische cesuur die zich in het zeventiende-eeuwse Europa voltrekt. ${ }^{25}$ Hij geldt als de filosoof die het verstand waardeert boven de onbetrouwbare zintuigen, ondanks het feit nieuwe instrumenten zoals telescoop en microscoop het bereik van onze zintuigen uitbreiden. Wetenschaps- en kunsthistorici hebben er al eerder op gewezen dat dit een te simpele voorstelling van zaken is. In plaats van te breken met Aristoteles, wedijverde Descartes juist met hem in het voltooien van de praktische natuurkennis. ${ }^{26}$ Daarnaast ontwikkelde hij een visueel-geometrische notatie als methode om tot een zeker oordeel te komen over de Natuur. ${ }^{27}$ De Wetenschappelijke Revolutie blijkt geen plotselinge en allesomvattende omwenteling te zijn, maar onderdeel van een gefaseerde transformatie die vanaf de vijftiende eeuw een 'wereld van precisie' ontvouwde. ${ }^{28}$ De kunst van het schilderen ontwikkelde zich tot een natuurfilosofisch kennissysteem waarin de potenties van verfstoffen, oog, geheugen, verstand en hand werden geordend. Deze praktische 
natuurkennis verschilt blijvend van de nieuwe natuurwetenschappen die zich gaan buigen over de aard van bewegingen in de natuur en die uitmondden in de wet van Newton over de zwaartekracht.

Daarmee kom ik bij de tweede aanname. Goethes Kleurenleer uit I8Io is nog in hoge mate schatplichtig aan die praktische natuurkennis. Ze schenkt aandacht aan kleuren in de natuur, aan waarneming, pigmenten, kleurmenging, betekenistoekenning en aan filosofie. Goethes bijdrage aan de esthetische revolutie is dus niet tot zijn filosofische overwegingen te reduceren, zoals Heumakers meerdere malen suggereert. ${ }^{30}$ Iets dergelijks geldt ook voor dichter Charles Perrault. Heumakers gaat voorbij aan het feit dat Perrault, de aanstichter van de zogenaamde Querelle des Anciens et des Modernes die in r687 aan de Franse Academie losbarstte, een broer had die architect was. Deze Claude Perrault introduceerde in zijn Franse vertaling (1673) van Vitruvius' De Architectura (33 v. Chr.) een onderscheid tussen relatieve en absolute schoonheid..$^{3}$ Dit onderstreept dat het nadenken over schoonheid niet louter een 'talige' zaak van achttiende-eeuwse filosofen en dichters was. En het bevestigt bovendien dat de dubbele 'esthetische revolutie' die Heumakers te berde brengt in feite over een beperkt domein van kennis gaat, namelijk het domein van woord of tekst en niet het domein van visuele beelden of schilderen.

Dat deze beperkte visie waarbij filosofen de tekst centraal stellen vanaf de negentiende eeuw breed ingang vond in het denken over beeldende kunsten mag een mirakel lijken. Al langer verwonder ik me over het feit dat juist de beeldvijandige Plato als schutspatroon van met name de naoorlogse kunstgeschiedenis fungeert. ${ }^{32}$ Heumakers genealogie maakt duidelijk dat filosofen als Shaftsbury, Hemsterhuis, Moritz, Schiller, Novalis en Schlegel een uitgesproken platoons denkkader hanteerden, waarin niet de materiële stof maar de ideale vorm, niet de laag-bij-de-grondse zintuigen of ambachtelijke techniek, maar de rede en het verheven idee van autonome Schoonheid een centrale rol spelen. ${ }^{33}$ Het is dit romantisch-moderne kunstbegrip dat zijn weg naar de kunstacademies, de kunstgeschiedenis en uiteindelijk de burgerlijke elite vond. Hoewel dit ambigue kunstbegrip vanaf de negentiende eeuw ook leidde tot een wispelturige (financiële) waardering van beeldende kunst, zoals Merlijn Schoonenboom onlangs aantoonde, bleef het heilige geloof in het Schone en de Kunst bestaan. Wie de eeuwigheidswaarde van dit kunstbegrip ter discussie stelt, raakt onmiddellijk aan een taboe. Het is spijtig dat Heumakers de eigen ontwikkeling in het denken over beeldende kunst, door zijn focus op filosofie en poëzie, te weinig onderkent.

Overigens is zijn boek de vrucht van een lange weg. Heumakers begon eraan in I988 en voltooide het 2015 als proefschrift aan de Universiteit van Amsterdam bij Bram Kempers (sociologie van de kunst) en Pim den Boer (Europese geschiedenis). Door zijn decennialange onderdompeling in het denken van vooral Duitse filosofen heeft Heumakers een overweldigend werk geschreven dat voor niet-filosofen spijtig genoeg nauwelijks te volgen is. Gegeven het belang van zijn beweringen zou het door hem vergaarde materiaal een minder chronologisch, minder anekdotisch en meer gestructureerd betoog vergen, juist om vat te krijgen op alle hoedanigheden waarin dat kunstbegrip zich tot op heden manifesteert. ${ }^{34}$ Voor kunst- en mediahistorici is de achttiende-eeuwse esthetische discussie bovendien te zeer gefixeerd op taal - met poëzie als ultieme Kunst - terwijl filosofische referenties naar de beeldende kunst te sporadisch voorkomen om relevant te zijn. Een serieuze geschiedenis die de transformatie 'van de kunst van het schilderen naar het denken óver Kunst'35 behandelt, moet 
nog worden geschreven en vereist, zoals Heumakers zelf ook beaamt, een compleet nieuwe studie die afrekent met allerlei anachronismen in de kunst- en cultuurgeschiedenis. ${ }^{36}$

\section{Bij wijze van accolade}

De tegenwoordige gewoonte van filosofen en kunstenaars om naar elkaars werken te verwijzen, zich aan elkaar te spiegelen en samen een enigmatische wereld in stand te houden, berust op een monsterverbond dat al geruime tijd bestaat. Kunst is in het Westen verworden tot een elitair en filosofisch gezelschapsspel waarvan het culturele belang, de esthetische waarde, de diepzinnige reflectie en het ethisch gehalte zelden ter discussie staan. ${ }^{37}$ Alle denkers die de Kunst verdedigen, van een conservatief als Roger Scruton tot een liberaal als Martha Nussbaum, hanteren hetzelfde romantische kunstbegrip, inclusief het pleidooi voor een 'esthetische opvoeding' en een gedeeld wantrouwen tegenover de nieuwe media of de 'alom oprukkende commerciële' populaire massacultuur. ${ }^{8}$ De zogeheten culturele studies zijn van dit gezelschapsspel slechts het zoveelste product. Ook zij hechten onvoorwaardelijk geloof aan het romantisch kunstbegrip ook al keren zij de gangbare waardering om doordat ze Kunst als 'hoge burgerlijk, elitaire cultuur' afwijzen. Zo verdedigde Ginette Verstraete tijdens haar oratie in 200I cultural studies omdat

men weigert de literaire cultuur en de intellectuele geschiedenis van de hogere bourgeoisie te naturaliseren tot 'de' ... cultuur. Men weigert de smaak en de levensstijl van één klasse als vanzelfsprekend te veralgemenen tot 'de nationale cultuur'. In plaats van 'de cultuur' spreekt men van 'onbewuste structuren', 'dominante praktijken', of, in het geval van (Raymond) Williams, van 'interactie tussen culturen', waarbij cultuur dan niet langer staat voor hogere kunst, eeuwige schoonheid of de productie van ware ideeën, maar voor wat Williams omschrijft als 'a whole way of life', zeg maar de vele levensvormen die er in een samenleving naast elkaar bestaan en die ook ruimte bieden voor betekenisvolle dagelijkse praktijken van arbeidersklassen, jongeren en vrouwen. ${ }^{39}$

Door zich uit te spreken voor de andere 'lage' kant en onvoorwaardelijk te kiezen voor alle uitgeslotenen, door het verheerlijken van massacultuur en door alles van klassieke kwaliteit te willen opblazen, houdt cultural studies de bipolaire logica van het modern-romantische kunstbegrip slechts in stand. $4^{\circ}$ Daarmee geven de postmodernen hooguit een nieuwe slinger aan de pendule-beweging die al meer dan twee eeuwen gaande is. Hoewel ze van zichzelf denken dat ze het dominante kunstbegrip op een kritische manier benaderen, bestendigen en naturaliseren ze dat juist.

Hoewel men niet kan zeggen dat het bij deze Noord-Europese transformatie van het kunstbegrip om een historische vergissing gaat, ${ }^{4 \mathrm{I}}$ blijft het gevoel bestaan dat de geschiedenis ons collectief een loer draaide. In feite hebben filosofen vanaf de achttiende eeuw en via de band van de autonome Schoonheid, zichzelf van een nieuwe legitimatie willen voorzien. Ze wilden terugkeren naar de rol die hen in de klassieke natuurfilosofie toekwam en die hen aan het eind van de vroegmoderne tijd door de Wetenschappelijke Revolutie ontvallen was. Dat wetende, is het beter om het filosoferen óver Kunst voorlopig te laten voor wat het is. Laten we over die historische plooi heenstappen en de draad op pakken waar filosofie die in de 
achttiende eeuw uit eigenbelang losliet. Het kan in deze tijden beslist geen kwaad om de waarde en het gewicht van beelden systematisch te doordenken en dan aan te knopen bij de tot in de vroegmoderne tijd gehanteerde trits van het-Goede-het-Ware-het-Schone. ${ }^{42}$ Want al die nieuwe beelden en media die er sinds de achttiende eeuw bij kwamen, kennen hun eigen substanties, conventies en vormenleer. Ze maken op specifieke wijze aanspraak op ons brein, onze gevoelswereld en ons culturele kijkkader. Het ontwikkelen van een nieuw denkkader is meer geboden dan ooit. Zolang we dat niet doen blijft alles wat de eigentijdse beeldwereld aangaat - met dank aan de filosofen en hun postmoderne epigonen - ongedacht, weggezet, gewist of op één hoop gegooid.

\section{Heidi de Mare, Stichting IVMV, Instituut voor maatschappelijke verbeelding}

\section{Noten}

I. Arnold Heumakers, De esthetische revolutie. Hoe Verlichting en Romantiek Kunst uitvonden (Amsterdam: Boom, 2015), 357 .

2. Ibidem, I6.

3. Heumakers beweert bovendien: 'Maar Kant was niet in de eerste plaats geïnteresseerd in esthetica, laat staan in kunst; het ging hem om de eenheid van zijn kritische of transcendentale systeem, dat met zijn zekerheid de mens weer een stabiel "thuis" moest verschaffen in het oneindig geworden universum - een centraal motief dat terugkeert in de Romantiek.' Ibidem, 20. Zie ook: Jabik Veenbaas, De verlichting als kraamkamer. Over het tijdperk en zijn betekenis voor het heden (Amsterdam: Nieuw Amsterdam, 2013).

4. Heumakers, De esthetische revolutie, 2I-22. Hij beschrijft dit in drie delen: deel I betreft de vraag hoe de autonomie vanaf Descartes denkbaar is geworden, deel II het loskoppelen van elk nut, en deel III is gewijd aan de Frühromantik, waarin enerzijds de poëtische redding wordt geformuleerd, anderzijds ook de nihilistische keerzijde van het romantisch vertrouwen in de poëzie. Ibidem, 20.

5. Ibidem, I9.

6. Ibidem, I6; 355 .

7. Ibidem, 357.

8. Heumakers zegt hier in het bijzonder over: "Begrippen als "kunst" en "literatuur" zijn niet eeuwig en tijdloos als platoonse ideeën, maar historisch en contingent, als eindige grootheden gebonden aan een bepaalde periode van de geschiedenis.' Ibidem, I7.

9. Ibidem, I6-I9.

Io. Parafraserend ontleend aan: Peter Henk Steenhuis en René Gude, Door het beeld. Door het woord (Leusden: ISVW, 20I5), vetgedrukte accentuering door recensent.

II. Genoemd worden naast Plato, Spinoza, Goethe, Schiller, Schopenhauer ook Karl Barth, Foucault, Nietzsche, Sloterdijk, Charles Taylor en Johan Huizinga. Naast primatoloog Frans de Waal passeren allerlei journalistieke wetenswaardigheden rondom relativiteitstheorie, geneeskunde en neurowetenschap. Verder wordt door de geïnterviewde kunstenaars beweerd dat kunstgeschiedenis een fictief verhaal, een ballast is, terwijl zij zich tegelijk vanzelfsprekend blijven verhouden tot oude en nieuwe meesters als Vermeer, Rembrandt, Zurbaran, Caspar David Friedrich, Van Gogh en Picasso.

I2. Ibidem, 298-299.

I3. René Gude en Wim Brands, Sterven is doodeenvoudig: Iedereen kan het (Leusden: ISVW, 20I4), I8.

I4. Steenhuis en Gude, Door het beeld, 322.

I5. Ibidem, 324; 330 .

I6. Ibidem, 323; 360.

I7. Gude zegt hierover: 'Iedere criticus - en ik heb het nu eens niet over de kunstcriticus, die veel beschimpte diersoort, maar over de kritische kunstenaar zelf - zou zich bewust moeten zijn van het moralisme dat in alle kritiek schuilt. Hij of zij zou zich daarover moeten uitlaten door verantwoording van vertrekpunten en intenties van de beste bedoelingen. Een hachelijk mijnenveld waar je veel kostbare tijd kunt verprutsen, en in die regionen kunnen kunstenaar en filosoof samen optrekken'. Ibidem, 326. 
I8. Ibidem, 309 .

I9. Ibidem, 349 .

20. Ibidem, 371; 342 .

2I. Ibidem, 338. Elders zegt Gude: 'Het is een fictie dat je een volledig wereldbeeld - voor de levenloze natuur, de levende natuur en de psychologisch, sociologisch en economisch begrepen cultuur - kunt optrekken met alleen aandacht voor het spul dat wij “Materie” noemen.' Ibidem, 3I4.

22. Ibidem, 346-347. Provocerend beweert Gude bovendien: 'In die antiburgerlijke en anti-traditionele stemming, waaraan de avant-garde, de intelligentsia en geleidelijk het hele volk van hoogst unieke individuen ten prooi is gevallen, is ambacht in diskrediet geraakt. Dat weet ik uit ondervinding, ik ben in de seventies ook opgegroeid tot zo'n origineel individu. (...) Ik ben gek op Jack “the dripper” Pollock en Karel Appel, en bij die jongens laat je het wel uit je hoofd te zeggen "knap gemaakt".' Ibidem, 34I.

23. Hij stelt namelijk dat: "Hoe harder men zich tegen de "Romantiek" in welke gedaante dan ook verzette, des te meer beantwoordde dat verzet aan het romantisch-moderne kunstbegrip, waarin totalisering en verabsolutering van de kunst, romantische engagement en l'art pour l'art niet zozeer twee onverenigbare tegengestelden zijn als wel twee zijden van dezelfde medaille.' Heumakers, De esthetische revolutie, 351.

24. Zie bijvoorbeeld: Maarten Doorman, De Romantische orde (Amsterdam: Bert Bakker, 20I2), I2I-I48. Door uit te wijken naar de ironie, tracht Doorman de Kunst en het romantisch-moderne kunstbegrip alsnog te redden. Zie ook: Merlijn Schoonenboom De nimf en de bunny: De wonderbaarlijke reis van een schilderij van kunst naar kitsch en weer terug (Amsterdam: Atlas Contact, 20I5). Interessant is hoe Schoonenboom, aan de hand van de wispelturige lotgevallen van 'Nymphes et satyre' (I873) van de Fransman William-Adolphe Bouguereau, de moderne kunstwereld beschrijft waarin we zijn gevangen.

25. Heumakers, De esthetische revolutie, 36, 67, 71; Steenhuis en Gude, Door het beeld, 338.

26. H. Floris Cohen, The Scientific Revolution. A Historiographical Inquiry (Chicago \& London: University of Chicago Press, I994), I62. Zie voor een bespreking hiervan: Heidi de Mare, Huiselijke taferelen. De veranderende rol van het beeld in de Gouden Eeuw (Nijmegen: Vantilt, 2012), 75-94; 485-500.

27. Zie onder andere: Bruce Stansfield Eastwood, "Descartes on Refraction: Scientific versus Rhetorical Method", in The Scientific Enterprise in Early Modern Europe. Readings from Isis, red. Peter Dear (Chicago \& London: University of Chicago Press, 1997), I54-175.

28. Cohen, 506-525.

29. Dit onderscheid kan ook verklaren waarom Newton zich daarnaast ook bezigheid met alchemie, een domein dat pas in de moderne tijd als onwetenschappelijke kennis werd gezien.

30. Heumakers, De esthetische revolutie, 140; 165; I74.

3I. Zie bijvoorbeeld: Liane Lefaivre en Alexander Tzonis, Theorieën van het architektonies ontwerpen (Nijmegen: SUN, I984).

32. Zie bijvoorbeeld hoofdstuk 5.2 over de geschiedenis van kunstgeschiedenis als wetenschap, in: Heidi de Mare, Het huis en de regels van het denken. Een cultuurhistorisch onderzoek naar het werk van Simon Stevin, Jacob Cats en Pieter de Hooch (dissertatie VUA, 2003), aldaar 649-706.

33. Heumakers, De esthetische revolutie, 40, I06, IIO, I56, I60, 274.

34. 'Aan de andere kant ben ik diep onder de indruk geraakt van de rijkdom van het romantisch-moderne kunstbegrip. De wendbaarheid en veelzijdigheid ervan kunnen beter niet worden onderschat.' Ibidem, 36r.

35. Zie voor een aanzet hiertoe hoofdstuk 4.2.4 en 5.I over de geschiedenis van vroegmoderne wetenschap en kunsten, in Heidi de Mare, Het huis en de regels van het denken, aldaar 577-587; 59I-647.

36. Heumakers, De esthetische revolutie, 353 .

37. Gevestigde belangen in de kunstwereld - academische kunstgeschiedenis, museum en markt - verklaren ook de weerstand die Heumakers bespeurt in zijn pleidooi de herkomst van het vigerende kunstbegrip onder de loep te nemen. Ibidem, I8.

38. Voor Heumakers' uitleg van beide aspecten van het romantische-moderne kunstbegrip, zie respectievelijk: Ibidem, I89-22I; 36I n. 5. Voor een bespreking van Scruton en Nussbaum, zie Heidi de Mare, "Waar is de verbeelding gebleven?" in Onder de motorkap van de modernisering, red. Thijs Jansen en Merlijn van Hulst (Amsterdam: Boom, 2015), I83-I9I.

39. Ginette Verstraete, Verstrooide burgers: Europese cultuur in een tijdperk van globalisering (Amsterdam: Vossiuspers, 200I), I6-I7.

40. Zie ook mijn besprekingen: Heidi de Mare, "ACW of de geruisloze uitverkoop van een vakgebied”, in Waartoe is de universiteit op aarde?, red. Ad Verbrugge en Jelle van Baardewijk (Amsterdam: Boom, 20I4), I87-I94; Idem, 
"Deconstructie van het fenomeen culturele studies", in Designgeschiedenis Nederland (2010), http://www.designhistory. nl/wp-content/uploads/2010/08/deconstructie_culturele_studies_hdm_20Io.pdf.

4I. Heumakers beweert namelijk: 'Bij hem (Schaefer) krijg je de indruk dat er sprake is geweest van een historische vergissing, die nu zo snel mogelijk ongedaan moet worden gemaakt. Maar kan de geschiedenis zich vergissen? Wel is het zo dat zij bestaat uit verandering, en dat betekent dat we onze verwachtingen en pretenties moeten bijstellen. Dat, zou ik zeggen, is nu aan de orde.' Heumakers, De esthetische revolutie, 362.

42. Zoals ook het aanknopen bij de klassieken onvermoede nieuwe inzichten biedt voor film en televisieserie, zie mijn dubbelbespreking van o.a. David Rijser, Een telkens nieuwe oudheid. Of: hoe Tiberius in New Jersey belandde (Amsterdam: Amsterdam University Press, 20I6) in Geschiedenis, beeld Q verbeelding, no. 4 (20I7) in voorbereiding, themanummer van het online magazine van de Stichting IVMV: http://www.maatschappelijkeverbeelding.nl/.

\section{Biografie}

Heidi de Mare is beeldwetenschapper, opgeleid in kunstgeschiedenis en filmwetenschap. Tussen I984-20II was zij als universitair docent verbonden aan diverse Nederlandse Letterenfaculteiten, aan Bouwkunde (TU Delft) en Medical Humanities (VUmc). In 2003 is zij cum laude gepromoveerd op een comparatief onderzoek naar vroegmoderne kunsten (handelseditie Huiselijke taferelen. De veranderende rol van het beeld in de Gouden Eeuw, Vantilt 2012). Sinds 2007 onderzoekt ze enerzijds de genealogie van het Europese kunstbegrip, anderzijds de eigentijdse rol van beeld en verbeelding in de publieke sfeer. Voor publicaties zie: https:// independent.academia.edu/HeidideMare. Sinds 2009 treedt zij op als directeur van de Stichting IVMV, Instituut voor maatschappelijke verbeelding. 